\section{Patient and provider perceptions of a novel cognitive functioning report for patients with systemic lupus erythematosus: a qualitative study}

\author{
Laura Plantinga (D) , , ${ }^{1,2}$ Ann Vandenberg, ${ }^{1}$ Felicia Goldstein, ${ }^{3}$ Brian Jones, ${ }^{4}$ \\ Jeremy Johnson, ${ }^{4}$ Christopher Barrett Bowling, ${ }^{5,6}$ Charmayne Dunlop-Thomas, ${ }^{1}$ \\ Sung Sam Lim (D) , ${ }^{1,2}$ Cristina Drenkard (D) ${ }^{1,2}$
}

To cite: Plantinga L,

Vandenberg A, Goldstein F, et al. Patient and provider perceptions of a novel cognitive functioning report for patients with systemic lupus erythematosus: a qualitative study. Lupus Science \& Medicine 2021;8:e000476. doi:10.1136/ lupus-2021-000476

Received 7 January 2021 Accepted 4 February 2021

\section{Check for updates}

(C) Author(s) (or their employer(s)) 2021. Re-use permitted under CC BY-NC. No commercial re-use. See rights and permissions. Published by BMJ.

${ }^{1}$ Department of Medicine, Emory University School of Medicine, Atlanta, Georgia, USA

${ }^{2}$ Department of Epidemiology, Rollins School of Public Health Emory University, Atlanta, GA, USA

${ }^{3}$ Department of Neurology, Emory University School of Medicine, Atlanta, Georgia, USA ${ }^{4}$ Interactive Media Techology Center, Georgia Institute of Technology, Atlanta, Georgia, USA

${ }^{5}$ Durham Veterans Affairs Geriatric Research Education and Clinical Center, Durham Veterans Affairs Medical Center, Durham, NC, USA

${ }^{6}$ Department of Medicine, Duke University, Durham, NC, USA

Correspondence to Dr Laura Plantinga; laura. plantinga@emory.edu

\section{ABSTRACT}

Objective To determine whether and how cognitive assessment data should be included in a report for patients with SLE and their providers.

Methods Leveraging experiences from prior studies, we created a cognitive report that included a hypothetical patient's results on tests of multiple domains based on the NIH Toolbox Fluid Cognition Battery. In focus groups that comprised patients with SLE (two groups) and their providers (two groups), feedback was sought on the presentation of results as well as the potential value of the report in the clinical setting.

Results Feedback regarding the presentation of the report was generally positive. Both patients with SLE and their providers liked its simple graphics and use of a colourgradated scale to indicate performance. However, both groups stressed the importance of using non-stigmatising language in describing results. Several potential purposes of the report, including distinguishing cognitive versus other issues, explaining cognitive challenges, improving patient-provider interactions, guiding decision-making, improving functioning or preventing impairment and tracking cognitive function over time, were noted by the participants. Potential barriers, such as inadequate clinical staffing or time and lack of potential treatments for identified issues, were also discussed.

Conclusion In this exploratory study, we found that both patients with SLE and their providers were receptive to the idea of a patient-friendly report of cognitive test results. This study provides important information to guide future pragmatic research to optimise the delivery of cognitive information to patients with SLE.

\section{INTRODUCTION}

Cognitive impairment in patients with SLE, often described as a 'lupus fog', has been reported in up to $50 \%$ of patients with SLE. ${ }^{1-6}$ This impairment may limit independence and reduce quality of life for patients with SLE, regardless of age. Despite its importance, cognitive functioning is not well described in most medical charts ${ }^{7}$ and often

\section{Key messages}

What is already known about this subject?

- Patients with SLE commonly report cognitive impairment, often described as 'lupus fog'.

What does this study add?

- This study explores patient and provider reactions to a patient-friendly report of cognitive functioning for SLE.

How might this impact on clinical practice or future developments?

- The report could potentially be used by SLE patients and providers to identify and articulate cognitive problems, seek needed referrals and guide shared decision-making.

not discussed in the clinical setting. Specific tools to improve the recognition of cognitive impairment and facilitate its discussion are currently lacking in SLE.

To address this gap, we leveraged our experiences in (1) creating a physical functioning report from a previous study in patients receiving dialysis ${ }^{8}$ and (2) completing detailed cognitive assessments as part of a pilot study of functioning in patients with SLE (Approaches to Positive, Patient-centered Experiences of Aging in Lupus; APPEAL) ${ }^{9}$ to create a prototype cognitive functioning report for patients with SLE and obtain feedback on the value and presentation of the report. Our objective was to determine whether and how cognitive assessment data should be included in a functioning report for patients with SLE and their providers.

\section{METHODS}

Study design and patient involvement

Four 90 min focus groups (two SLE patient $(\mathrm{n}=18)$ groups and two SLE provider 


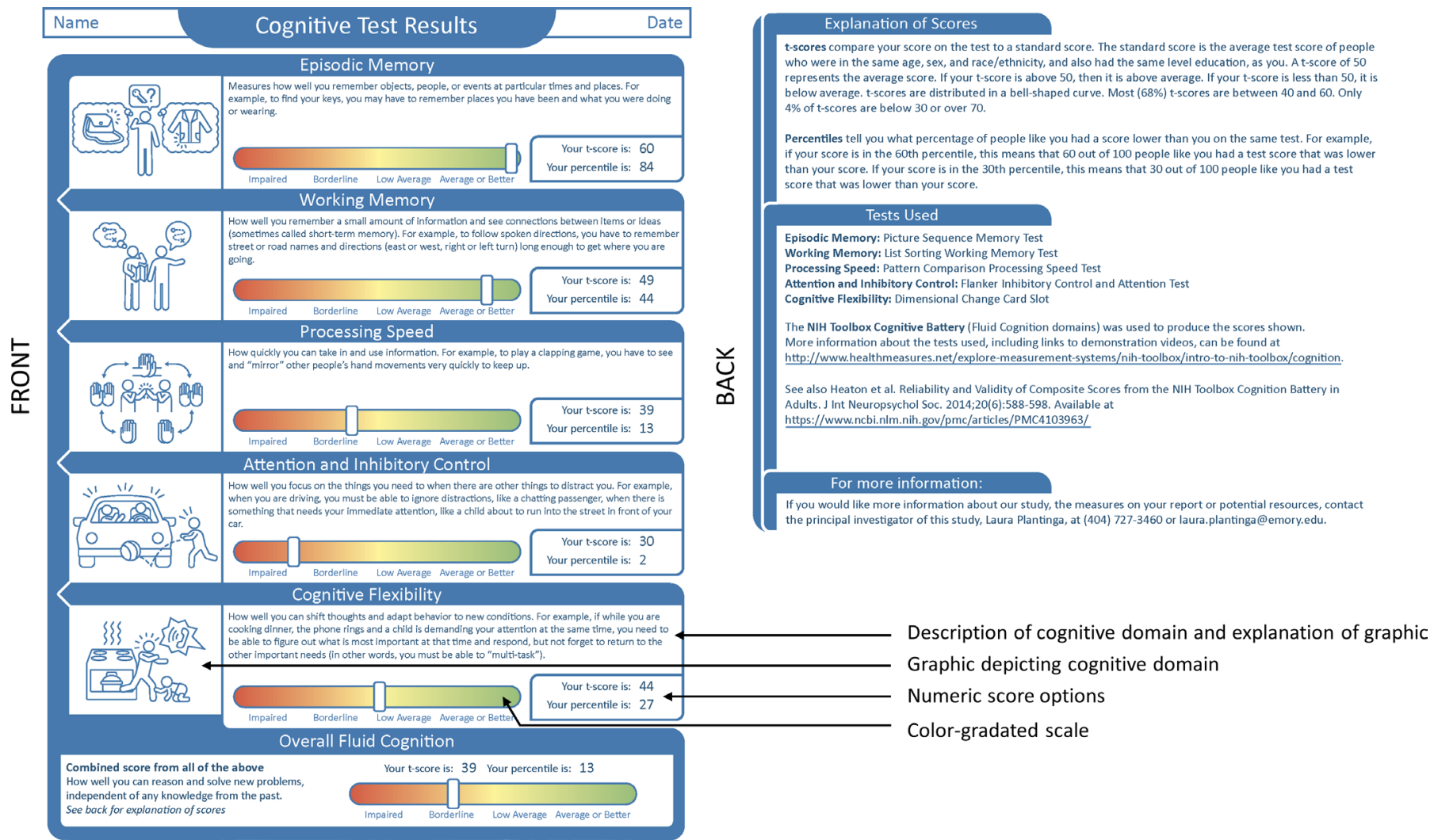

Figure 1 Cognitive functioning report for a hypothetical patient with SLE, as presented to focus groups.

groups $(n=9))$ were held in 2019. Patient participants were recruited from the APPEAL pilot, ${ }^{9}$ representing a subsample of the population-based Georgians Organized Against Lupus cohort ${ }^{10}$; provider participants (physicians, nurses, medical assistants) were recruited from the local provider population based on their experience with patients with SLE. While the initial prototype report was created by the study team, without patient involvement, these focus groups were designed to identify patient and provider priorities for the report of cognitive functioning information in future pragmatic research and ultimately clinical care.

\section{Data collection and analysis}

Development of the cognitive functioning report

Based on a physical functioning report piloted in a population of patients receiving dialysis, ${ }^{8}$ our goal was to create a patient-friendly report for patients with SLE (figure 1). The domains of cognitive functioning included episodic memory, working memory, processing speed, inhibitory control and attention, and cognitive flexibility and were based on the NIH Toolbox ${ }^{11}$ assessments that were performed in the APPEAL pilot study. ${ }^{9}$ Everyday examples of tasks involving these cognitive domains were listed, discussed and selected by the entire team over the course of several meetings; the chosen examples were illustrated and provided along with a written description (figure 1). To gather feedback on preferred presentation of performance/scores, the hypothetical patient's performance was displayed as both a colour-gradated scale with categories of 'impaired', 'borderline', 'low average' and 'average or better' and as numeric scores, including age, sex, race, ethnicity and education-adjusted t-scores $($ mean $=50, \mathrm{SD}=10)$ with associated percentiles. Further explanations were provided on the back of the report (figure 1).

\section{Focus groups}

The focus groups included two phases: (1) an open discussion of cognitive problems and general interest in discussing cognition in clinic (Vandenberg et al, submitted) and (2) a discussion of the potential value of a cognitive report in a clinical setting as well as the specific presentation of domains and scores on the cognitive report. Focus group sessions were digitally recorded and transcribed. Transcripts were analysed (by AV) thematically ${ }^{12}$ with open coding, ${ }^{13}$ followed by focused coding using NVivo V.12 Plus (QSR International, Burlington, Massachusetts) data management and visualisation software.

\section{RESULTS}

\section{Focus group participants}

The patient participants had a mean age of 51 and were predominantly female $(83 \%)$ and Black $(83 \%)$, and the mean duration of SLE was 20 years. The provider participants had a mean age of 40; $89 \%$ were female and $33 \%$ were Black. The provider participants reported a mean of 6 years of experience treating SLE. 
Table 1 Patient and provider feedback on potential value of shared information about cognition for patients with SLE

Representative quote

\begin{tabular}{|c|c|c|}
\hline Purpose & \multicolumn{2}{|l|}{ Representative quote } \\
\hline $\begin{array}{l}\text { Distinguishing cognitive } \\
\text { problems from other issues }\end{array}$ & $\begin{array}{l}\text { 'You wonder okay, now, if I'm having something } \\
\text { else going on or if it's a lupus fog.' }\end{array}$ & $\begin{array}{l}\text { 'It would be really helpful to understand if it } \\
\text { is a real problem, or if it is their mood, or just } \\
\text { their perception.' }\end{array}$ \\
\hline Explaining cognitive problems & $\begin{array}{l}\text { 'I think it's helpful information because it does } \\
\text { break down the different types of memory loss, } \\
\text { like, 'cause I never thought about it. How it's } \\
\text { broke down.' }\end{array}$ & $\begin{array}{l}\text { 'They might feel a little bit less frustrated } \\
\text { if they can see that they do have some } \\
\text { cognitive impairment, and maybe that's why } \\
\text { they're having some trouble at work.' }\end{array}$ \\
\hline $\begin{array}{l}\text { Improving patient-provider } \\
\text { interactions }\end{array}$ & $\begin{array}{l}\text { 'I think it would break the ice. Sometimes } \\
\text { when you go to the doctor, you're scared or it } \\
\text { just doesn't come to you, certain things, you } \\
\text { may just wanna ask. With all of these different } \\
\text { segments....it will bring back some of the things } \\
\text { that you may have wanted to ask.' }\end{array}$ & $\begin{array}{l}\text { 'I think it would maybe help change maybe } \\
\text { how you counsel the patient. If they're more } \\
\text { cognitively impaired, maybe give them much } \\
\text { more simple instructions or involve the } \\
\text { family a little bit more.' }\end{array}$ \\
\hline $\begin{array}{l}\text { Improving cognitive } \\
\text { functioning or preventing } \\
\text { cognitive impairment }\end{array}$ & $\begin{array}{l}\text { '[l]t would be nice to know what I can prevent } \\
\text { now because luckily I'm still young. If there's } \\
\text { something I can do now to make it better when } \\
\text { I'm } 40,50,60 . . \text { I don't know, brain exercises.' }\end{array}$ & - \\
\hline $\begin{array}{l}\text { Monitoring cognitive function } \\
\text { over time }\end{array}$ & $\begin{array}{l}\text { '[Y]ou want to know if you've improved or if you } \\
\text { failed or if you slightly fell out, or whatever the } \\
\text { case might be.' }\end{array}$ & $\begin{array}{l}\text { 'This would be good in certain situations } \\
\text { especially if you have a patient that always } \\
\text { comes in and says they have the lupus fog, } \\
\text { to sort of track them.' }\end{array}$ \\
\hline
\end{tabular}

\section{Potential value of the cognitive report}

Table 1 describes several stated potential purposes of having information about SLE patient cognition, such as that provided in the cognitive report. General comments included 'I think it's going to be really helpful' (provider) and 'I would love to do this with my doctor' (patient). Specific to the report, both patients and providers voiced its potential to improve patient-provider interactions; patient participants envisioned the report as a communications tool: 'It actually gives them (providers) now a visual of what it is that you may have been trying to express.' While patient participants focused on the way that the report would initiate the conversation around cognition, provider participants focused more on how it would inform their communication with patients. In terms of guiding decision-making, both patients and provider participants mentioned follow-up referrals, and providers discussed the possibility of adjusting medications as needed.

Patient and provider participants also had unique perspectives on the potential value and challenges of using the proposed report. First, patients less often mentioned the possibility of using the report to distinguish cognitive problems from other issues. Providers also stated that, even with cognitive test results, it might be impossible to distinguish the effects of age-related or dementia-related cognitive decline from the effects of SLE (including musculoskeletal problems that hinder testing, distracting pain, fatigue or depression). Second, several patientbut no provider-participants mentioned the possibility of using the report to identify cognitive problems for prevention of further deterioration or improvement. A related anticipated problem was the potential lack of a solution to the cognitive problems identified in the report (eg, 'I would feel comfortable telling them (the results), as long as I had something for them to do to improve it' (provider)). Finally, providers voiced significant concern about not having the time and resources to add cognitive assessment into clinic visits: 'I'm not sure of how easy it would be in a clinic where I'm just the sole provider...if it was more of a multidisciplinary clinic, where you had nurses and social workers involved in the patient care, I think it would really work.'

\section{Presentation of the cognitive report}

The participants liked the overall appearance of the report, although a few patient participants suggested that the multiple results made it appear 'complex' at first glance. Feedback on graphic representations of cognitive domains was generally positive, with most participants understanding the tasks presented as relevant without the need for explanation. Table 2 presents feedback for 
Table 2 Patient and provider feedback on performance reporting in a shared format cognitive report for patients with SLE

Representative quote(s)

\begin{tabular}{|c|c|c|}
\hline Performance reported by: & Patients $(n=18)$ & Providers $(n=9)$ \\
\hline \multirow[t]{3}{*}{ Colour-gradated scale } & $\begin{array}{l}\text { '...a quick glance through the color coding and } \\
\text { the scale, it gives you a brief report as to where } \\
\text { you stand within these particular categories.' }\end{array}$ & $\begin{array}{l}\text { 'I like the color part too, and I think the patients } \\
\text { understand red being bad versus green being } \\
\text { better.' }\end{array}$ \\
\hline & $\begin{array}{l}\text { 'The word "impaired" makes you feel like you're } \\
\text { in dummy-mode.' }\end{array}$ & $\begin{array}{l}\text { 'I think the way it's laid out, actually being sort } \\
\text { of skewed with just "average or better" at the } \\
\text { top. Even with this patient that is } 27 \% \text { but } \\
\text { almost in the middle, so it actually looks better } \\
\text { than it really is.' }\end{array}$ \\
\hline & & $\begin{array}{l}\text { 'The only thing I would worry about is the } \\
\text { wording, like impaired, borderline, below } \\
\text { average... If I saw this and I was below } \\
\text { average... It might even make me more } \\
\text { depressed.' }\end{array}$ \\
\hline t-scores & $\begin{array}{l}\text { 'I think the whole t-score... is sort of confusing.' } \\
\text { 'Out of a } 100 \text { people they're...39.' (Representing } \\
\text { misunderstanding of the } t \text {-score) }\end{array}$ & $\begin{array}{l}\text { 'A t-score is going to be really confusing to } \\
\text { patients. And then the doctor is going to have } \\
\text { to spend a lot of time explaining what a t-score } \\
\text { is. Because even really well-educated patients } \\
\text { are not going to know what a t-score is.' }\end{array}$ \\
\hline Percentiles & $\begin{array}{l}\text { 'Well the percentage's okay but the t-score kind } \\
\text { of threw me off.' } \\
\text { 'I think some of us are probably more worried } \\
\text { about numbers because it's kind of like, it's } \\
\text { kind of like, labeling us. That's kind of a label, a } \\
\text { percentage score.' }\end{array}$ & $\begin{array}{l}\text { 'The percentile. It's easier. Patients like } \\
\text { percentages because they can remember it.' } \\
\text { 'If you're talking about which of these numbers } \\
\text { is better, percentile I think is a lot easier to } \\
\text { understand.' } \\
\text { 'Dealing with someone whose processing } \\
\text { information is 13th percentile and trying to } \\
\text { explain to them...it's really hard.' }\end{array}$ \\
\hline
\end{tabular}

the various presentations of the cognitive test results. Participants liked the simplicity of the colour-gradated scale, although some suggested changing the word 'impaired' to something less judgemental such as 'fair'. In addition, most patient and some provider participants viewed the colour-gradated scale as a more neutral way to present results than numeric scores. Across groups, many suggested that the colour-gradated scale alone should be the primary presentation of results, potentially with numeric scores on the back of the report for providers and patients who wish to track these results. For numeric scores, most participants had preferences for percentiles over t-scores, if numeric scores were presented (table 1). While both represent comparisons to the general population, with adjustment for age, sex, race/ethnicity and education, some patients expressed preferences to be compared with a lupus population or not to be compared with others at all (eg, 'The description says, "Like you." I don't know what is like me...').

\section{DISCUSSION}

In this exploratory study, we found that both patients with SLE and their providers were receptive to the idea of a patient-friendly report of cognitive test results. The report was seen by patients and providers as a tool to identify cognitive issues (or reassure patients of normal/stable functioning) and to facilitate better patient-provider interactions.

Importantly, this study, while limited by its qualitative nature and small sample size, identified several considerations for use of the report in the clinical or pragmatic research setting. First, expectations of patients with SLE regarding the potential for improvement in cognition should be managed. Few interventions to improve cognitive functioning have been studied in SLE to date; however, neither patients with SLE nor their providers mentioned the possibility of providing support (such as occupational therapy ${ }^{14}$ ) to help manage day-to-day tasks in the setting of cognitive impairment; education in this area of both 
patients and providers might be needed. Second, presentation of results is important; some patients with SLE may just want reassurance that functioning remains 'average or better', but other patients, and providers, may wish to track numeric results to identify longitudinal patterns. Third, the context of the clinical setting would have to be considered. Having providers on staff who feel comfortable discussing cognitive test results and have adequate time for the discussion is critical. Additionally, rheumatologists and primary care providers may wish to be aware of these issues to help guide their clinical decision-making, but they should also have the ability to refer a patient to a neurologist or other specialist specifically for further cognitive testing and/or to provide needed cognitive support. Partnership with geriatric providers could mitigate these issues by facilitating provider education and providing a cognitive support referral network.

In conclusion, these results provide important information to guide future pragmatic research to optimise the delivery of cognitive information to patients with SLE.

Acknowledgements We thank Amelia Lambeth for creating the graphics used in our cognitive report.

Contributors LP, SSL, CBB and CD designed the study. LP, AV, FG, BJ, JJ and CBB were involved in the design and execution of the report prototype. LP, AV and CDT were involved in the acquisition of data. AV analysed the data. $L P, A V, F G, C D T, B J$, JJ, SSL, CBB and CD reviewed the manuscript for intellectual content and approved the final manuscript.

Funding This work was supported by the US Army Medical Research Acquisition Activity (USAMRAA) through the Congressionally Directed Medical Research Programs (CDMRP) under Award No W81XWH1810619 (to LP). GOAL is supported by the Centers for Disease Control and Prevention (Grant No U01DP006488 to SSL and $\mathrm{CD}$ ).

Disclaimer Opinions, interpretations, conclusions and recommendations are those of the authors and are not necessarily endorsed by the Department of Defense.

Competing interests None declared.

Patient and public involvement Patients and/or the public were not involved in the design, or conduct, or reporting, or dissemination plans of this research.

Patient consent for publication Not required.

Ethics approval The Emory Institutional Review Board and the Human Research Protection Office of the US Army Medical Research Acquisition Activity approved the study. All participants provided written informed consent.

Provenance and peer review Not commissioned; externally peer reviewed.
Open access This is an open access article distributed in accordance with the Creative Commons Attribution Non Commercial (CC BY-NC 4.0) license, which permits others to distribute, remix, adapt, build upon this work non-commercially, and license their derivative works on different terms, provided the original work is properly cited, appropriate credit is given, any changes made indicated, and the use is non-commercial. See: http://creativecommons.org/licenses/by-nc/4.0/.

\section{ORCID iDs}

Laura Plantinga http://orcid.org/0000-0003-0809-8981

Sung Sam Lim http://orcid.org/0000-0003-2361-0787

Cristina Drenkard http://orcid.org/0000-0002-6832-7291

\section{REFERENCES}

1 Hanly JG, Fisk JD, Sherwood G, et al. Clinical course of cognitive dysfunction in systemic lupus erythematosus. J Rheumatol 1994;21:1825-31.

2 Hanly JG, Fisk JD, Sherwood G, et al. Cognitive impairment in patients with systemic lupus erythematosus. J Rheumatol 1992;19:562-7

3 Kabat MH, Kane RL, Jefferson AL, et al. Construct validity of selected automated neuropsychological assessment metrics (anam) battery measures. Clin Neuropsychol 2001;15:498-507.

4 Hanly JG, Omisade A, Su L, et al. Assessment of cognitive function in systemic lupus erythematosus, rheumatoid arthritis, and multiple sclerosis by computerized neuropsychological tests. Arthritis Rheum 2010;62:1478-86.

5 Vogel A, Bhattacharya S, Larsen JL, et al. Do subjective cognitive complaints correlate with cognitive impairment in systemic lupus erythematosus? A Danish outpatient study. Lupus 2011;20:35-43.

6 Plantinga L, Lim SS, Bowling CB, et al. Perceived stress and reported cognitive symptoms among Georgia patients with systemic lupus erythematosus. Lupus 2017;26:1064-71.

7 Bogardus ST, Towle V, Williams CS, et al. What does the medical record reveal about functional status? A comparison of medical record and interview data. J Gen Intern Med 2001;16:728-36.

8 Plantinga LC, Jones B, Johnson J, et al. Delivery of a patient-friendly functioning report to improve patient-centeredness of dialysis care: a pilot study. BMC Health Serv Res 2019;19:891.

9 Plantinga L, Tift BD, Dunlop-Thomas C, et al. Geriatric assessment of physical and cognitive functioning in a diverse cohort of systemic lupus erythematosus patients: a pilot study. Arthritis Care Res 2018;70:1469-77.

10 Lim SS, Drenkard C. Understanding lupus disparities through a social determinants of health framework: the Georgians organized against lupus research cohort. Rheum Dis Clin North Am 2020;46:613-21.

11 Heaton RK, Akshoomoff N, Tulsky D, et al. Reliability and validity of composite scores from the NIH Toolbox cognition battery in adults. $J$ Int Neuropsychol Soc 2014;20:588-98.

12 Braun V, Clarke V. Using thematic analysis in psychology. Qual Res Psychol 2006;3:77-101.

13 Charmaz K. Constructing Grounded theory. 2nd Ed. ed. Los Angeles, London, New Delhi, Singapore, Washington DC: Sage, 2014.

14 Poole JL, Bradford JD, Siegel P. Effectiveness of occupational therapy interventions for adults with systemic lupus erythematosus: a systematic review. Am J Occup Ther 2019;73:7304205020p1. 